\title{
Is this hair professional enough?
}

Cite as: CMAJ 2021 February 16;193:E254-5. doi: 10.1503/cmaj.201871

was eight years old when my mother sent me to school with Bantu knots in my hair. This hairstyle, which originated with the Zulu people of southern Africa, was worn for centuries on the African continent before becoming widely adopted by the diaspora.

I returned home that afternoon in tears. My classmates, unaccustomed to a hairstyle of that sort, had spent all day laughing, pointing and comparing my hair to excrement. The tiny shred of pride I had had in my natural kinky-textured hair was crushed. I told my mother never to style it like that again and begged her for a chemical hair relaxer; she finally caved in about two years later.

I spent the ensuing years, into early adulthood, chemically straightening my hair and adopting a variety of protective styles: braids, cornrows, hair extensions and wigs. Women of African descent commonly use these styles to protect our hair from overmanipulation and to permit undisrupted growth of the hair.

Unfortunately, these styles, along with the use of chemical relaxers for permanent hair straightening, have been strongly linked to a form of hair loss known as traction alopecia. One study found that a third of Black women suffer from this condition, which can lead to permanent hair loss if not detected and treated early. ${ }^{1}$ In addition, Black women who use relaxers have been shown to have a higher likelihood of developing uterine fibroids. ${ }^{2}$

There is a general knowledge of the harm caused by these practices, but not much has been done to raise awareness on the topic in Black communities. In fact, it is often implied that in order to attain a certain level of professional and societal success, Black women must conform to Eurocentric standards of beauty by opting for straightened hairstyles over natural, Afro-textured ones. ${ }^{3}$ Like most Black

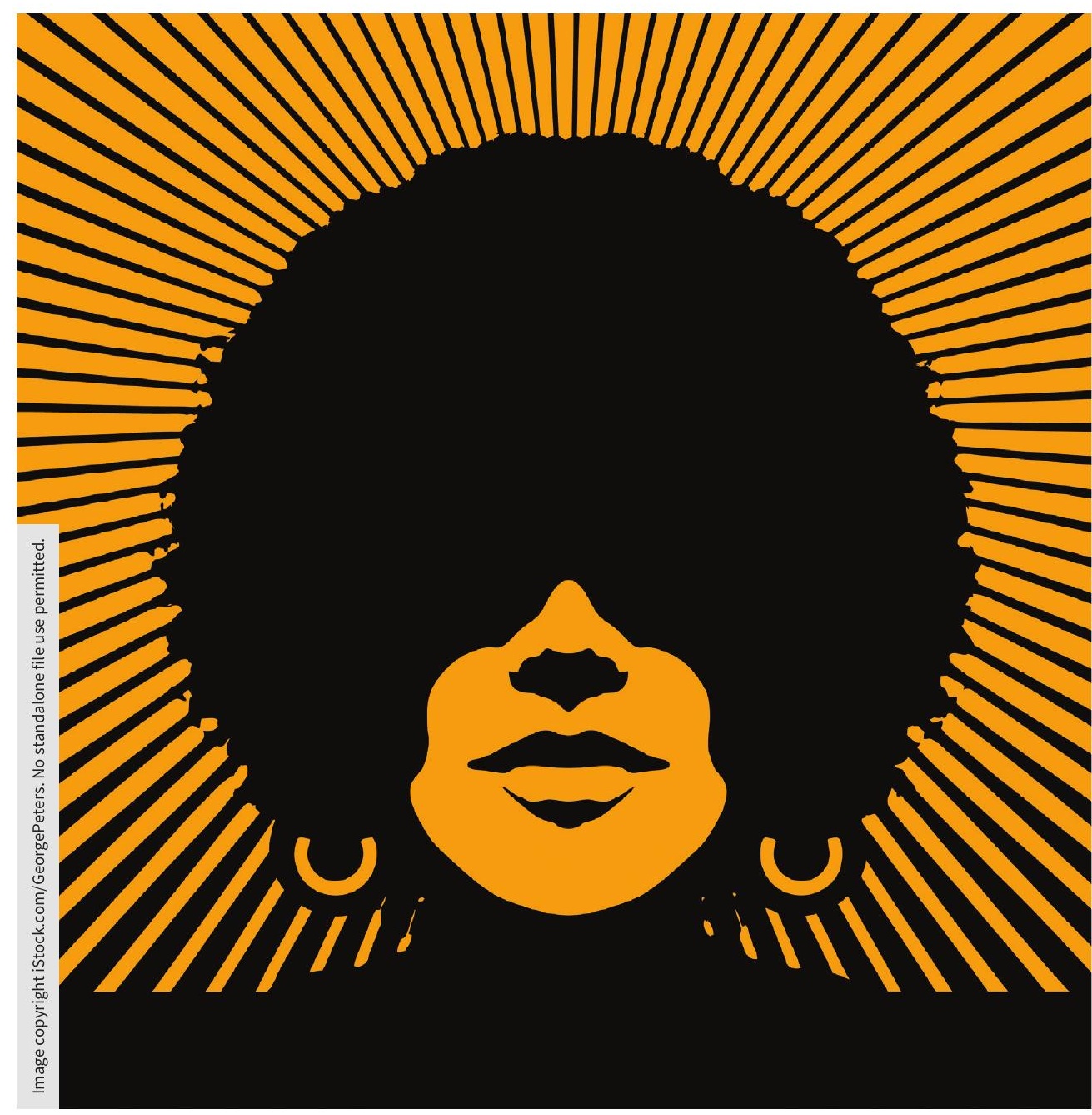

women in my environment, I subscribed to that belief and happily shelled out hundreds of dollars in pursuit of these looks.

The early 2000s saw a resurgence of the "natural hair movement" in Black communities around the globe. It originated during the Black Power movement of the 1960s, and uplifts and encourages people of African descent to wear their hair in its naturally wavy, curly or coiled state. YouTubers and natural-hair bloggers were instrumental in bringing to the masses the tools and information needed to properly care for and style Afro-textured hair.
The end of my undergraduate degree and the beginning of my journey in medicine coincided with this period of celebration of natural Black hair. After contemplating going natural for a while, I ultimately relaxed my hair again a few weeks before my first semester of medical school. Despite feeling inspired by the natural hair movement and aware of the dangers of chemical relaxers, I was still convinced that my straight hair and extensions were more acceptable for a medical setting and would allow me to blend in as much as possible. 
Two years into medical school, after numerous painful and costly braiding sessions and weave installations, I finally decided to go for the "big chop": all the relaxed ends were cut off, leaving only natural, unprocessed hair. I planned this cut to coincide with my summer vacation so as to avoid intrusive comments from colleagues about the drastic change. It was freeing to let go of those damaged strands and embrace my short, tightly coiled locks for the first time. After ten years of wearing hair extensions and chemically altering the texture of my hair, I had forgotten what my natural hair truly looked like.

When fall came, my newfound hairstyle was met with compliments and innocent curiosity by my peers. At the start of clerkship, however, I had qualms about whether my short Afro hair would be deemed professional enough for a clinical setting. On several occasions when I was mistaken for a nurse, an orderly or a janitor, I asked myself if - on top of my visibly Black skin - my hairstyle did not fit with society's image of a doctor-to-be.

My experience is, luckily, far from the worst. A 2018 study found that hair was a common theme associated with microaggressions experienced by minority resident physicians in the workplace. ${ }^{4}$ The United States Army made headlines in 2014 when its new grooming policy formally banned hairstyles such as Afros, braids and cornrows (www.huffingtonpost .ca/entry/army-hairstyle_n_5070180?ri18n =true). In 2013, a seven-year-old girl in Tulsa, Oklahoma, was sent home from school because her dreadlocks were deemed a distraction for her classmates (www.today.com/parents/school-barred-7 -year-olds-dreadlocks-changes-dress-code -policy-8C11122821). Instances such as these have led to the drafting of the CROWN Act: Create a Respectful and Open World for Natural Hair. It is currently law in seven American states and prohibits discrimination based on hairstyles and hair texture. ${ }^{5}$ Similar initiatives are needed elsewhere.

Now, as a fourth-year medical student with residency interviews around the corner, I cannot help but ponder how my image will be perceived by potential admissions committees. I've read stories of Black physicians who maintained straightened hairstyles until completing residency; only then would they allow themselves to explore natural styles. I've heard of candidates who purposefully wore hair extensions on interview day to maintain a professional image. While acknowledging that these are personal choices and not strictly the product of outside influence, we cannot deny that the culture of medicine has contributed to Black trainees' reluctance to let their hair be natural in professional settings.

Throughout our medical training, we are taught, implicitly and explicitly, to tone down our individuality in favour of adopting a more neutral, standardized image. But this image is the product of a bygone era when physicians were an exclusive group, mostly homogeneous in race and gender. People of colour who have since integrated into the field of medicine feel obligated to divest themselves of their cultural identity so as to adapt to this predominantly White space. Fortunately, a growing number of Black physicians are beginning to change this culture by unapologetically donning their natural hair in the workplace.

As our medical education system shifts toward being more inclusive, the formal policies and unspoken rules that govern the appearance of trainees must be updated accordingly. Drafters of dress codes should be mindful of their potential to perpetuate biases that implicitly centre whiteness, while disproportionately penalizing people of colour. Antidiscrimination policies should consider traits historically associated with race and culture, such as hairstyle and texture, as prohibited grounds of discrimination. It is time for the governing bodies of medicine to redefine professionalism in a way that not only includes but also celebrates the diverse backgrounds, identities and values present among today's physicians.

\section{Samantha Bizimungu BScKin}

Faculty of Medicine, Université de Montréal, Montréal, Que.

\section{References}

1. Loussouarn G, El Rawadi C, Genain G. Diversity of hair growth profiles. Int J Dermatol 2005; 44(Suppl 1):6-9.

2. Wise LA, Palmer JR, Reich D, et al. Hair relaxer use and risk of uterine leiomyomata in AfricanAmerican women. Am J Epidemiol 2012;175:432-40.

3. Bankhead T, Johnson T. Self-esteem, hairesteem and Black women with natural hair. Int $J$ Educ Soc Sci 2014;1:92-102.

4. Osseo-Asare A, Balasuriya L, Huot SJ, et al. Minority resident physicians' views on the role of race/ethnicity in their training experiences in the workplace. JAMA Netw Open 2018;1:e182723.

5. The CROWN Act [main page]. Available: www. thecrownact.com (accessed 2020 July 7).

This article has been peer reviewed.

Content licence: This is an Open Access article distributed in accordance with the terms of the Creative Commons Attribution (CC BY-NC-ND 4.0) licence, which permits use, distribution and reproduction in any medium, provided that the original publication is properly cited, the use is noncommercial (i.e., research or educational use), and no modifications or adaptations are made. See: https://creativecommons.org/ licenses/by-nc-nd/4.0/ 